\title{
Gunnar Franck
}

\section{Der Direktanspruch gegen den Haftpflichtversicherer}

Eine rechtsvergleichende Untersuchung zum deutschen und skandinavischen Recht

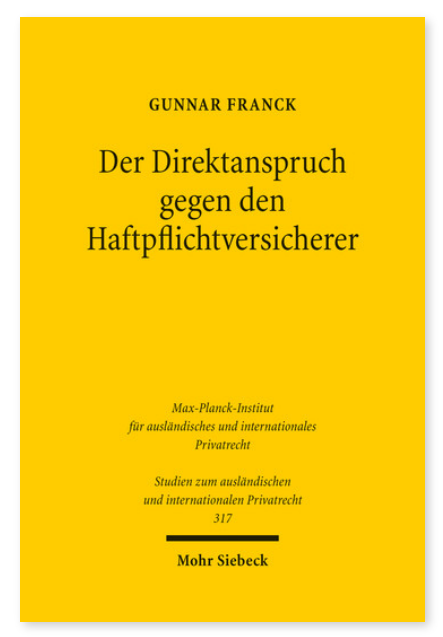

2014. XXIII, 235 Seiten. StudIPR 317

ISBN 978-3-16-153499-7

DOI 10.1628/978-3-16-153499-7

eBook PDF 79,00€

ISBN 978-3-16-153480-5

fadengeheftete Broschur 79,00€
Der Geschädigte nimmt in der Haftpflichtversicherung eine besondere Stellung ein: Sein Schadensersatzanspruch entspricht dem versicherten Risiko. Grundsätzlich kann der Geschädigte seinen Schadensersatzanspruch indes nicht direkt beim Haftpflichtversicherer geltend machen. Gunnar Franck untersucht rechtsvergleichend, inwieweit das deutsche und skandinavische Recht dem Geschädigten dennoch ermöglichen, unmittelbar gegen den Haftpflichtversicherer vorzugehen. Zudem analysiert er, wie die mit einer solchen Durchgriffshaftung einhergehen Probleme gelöst werden. Hierfür wird insbesondere auf die zentralen Fragen der Drittwirkung der Einwendungen des Versicherers und der Bindungswirkung des Haftungsverhältnisses eingegangen. Der Vergleich mit dem skandinavischen Recht fördert dabei Vor- und Nachteile einzelner Regelungsmodelle zu Tage.

Gunnar Franck Geboren 1983; Studium der Rechtswissenschaften an den Universitäten Halle-Wittenberg und Bergen (Norwegen); Master-Studiengang Wirtschaftsrecht in Halle (Saale); 2009 Abschluss LL.M.oec.; 2009-11 Referendariat in Hamburg, 2014 Promotion an der Universität Hamburg; Wissenschaftlicher Referent für Skandinavien und die Niederlande am Max-Planck-Institut für ausländisches und internationales Privatrecht in Hamburg.
Jetzt bestellen:

https://mohrsiebeck.com/buch/der-direktanspruch-gegen-den-haftpflichtversicherer-9783161534997?no_cache=1 order@mohrsiebeck.com

Telefon: +49 (0)7071-923-17

Telefax: $+49(0) 7071-51104$ 